\title{
Preparation and Characterization of Low Density Polyethylene-Chitosan Nanoparticles Biocomposite as a Source of Biodegradable Plastics
}

\author{
Oluwaseun A. Adelaja and Oluwatosin E. Daramola
}

\section{ABSTRACT}

Proper incorporation of natural polymers such as chitosan, starch, or cellulose in the matrix of non-degradable polymers has been proposed to bring about a possible lasting solution to the menace caused by nondegradable plastics in the environment. Biodegradable composite films of low-density polyethylene-chitosan nanoparticles (LDPE/CHNP) has been prepared by solvent casting method. The physiochemical, thermal, biodegradability and microbial inhibition test of the biocomposite have also been investigated to optimize the prepared composite. Physiochemical, thermal, and microbial inhibition rate has been found to increase with increase in chitosan nanoparticles (CHNP) loading in the prepared matrix. The mechanical studies showed that the tensile strength and elastic modulus increased with increasing loading of chitosan nanoparticles. The improvement in the mechanical properties have been attributed to the compatibility of the composite. The prepared LDPE/CHNP biocomposite film with $15 \%$ chitosan nanoparticles showed maximum elastic modulus of 23.10 and tensile strength of 3.52, as well as the best dispersion of particles as revealed by the morphological studies of the composite films. The result of the biodegradation study showed that the degradation efficiency and rate increased in CHNP loading with $20 \%$ CHNP loading having the maximum degradation efficiency of $50 \%$ and rate $0.12 \mathrm{~g} / \mathrm{d}$ after 21 days. The biocomposite film prepared has proved to be degradable, having antimicrobial properties, thereby it could act as an eco-friendly alternative to conventional non-degradable plastics and could be applied in food packaging, fuel cell and wastewater treatment.

Keywords: Biocomposites, Low density polyethylene, Chitosan nanoparticles, Biodegradation, Blending, Solvent casting.
Published Online: January 26, 2022

ISSN: $2684-4478$

DOI: 10.24018 / ejchem.2022.3.1.85

\section{O. A. Adelaja}

Department of Chemistry, School of Sciences, Federal University of Technology Akure, Nigeria.

(e-mail: oaadelaja@futa.edu.ng)

O. E. Daramola*

Department of Chemistry, School of Sciences, Federal University of Technology Akure, Nigeria.

(e-mail: oluwatosindaramola ${ }^{@}$ gmail.com)

*Corresponding Author

\section{INTRODUCTION}

Environmental pollution is a product of human inventions and activities which at the long run becomes a problem to humans and environment. Because the aftermath effect of some of man's inventions such as non-degradable plastics was not properly considered is the major cause of serious pollution of the environment. The use of plastic seems to be inevitable as it finds application for several purposes such as for packaging materials, food storage, transportation, shelter etc., but the negative effect is increasingly becoming unbearable for the environment.

As the release of plastic wastes to the environment is escalating there is a global concern because disposal systems are inadequate, incineration may result to release of toxic waste pollution, there are limited landfills, and recycling techniques for waste are too expensive and requires high energy consumption [1]. Coupled with the non-degradability of this plastics and their toxic effect on the environment is the amount of petroleum resource been rationed for the manufacture of these plastics. Low density polyethylene (LDPE), a low-cost material having excellent processability, and it is a major source of plastics used in manufacture of packaging products. But the non-biodegradability of LDPE has a major is concern, which has been calling attention for a long time now [2].

However, bioplastics being a degradable plastic, can probably replace the conventional plastics because it has a shorter time for its degradability. Bioplastics are renewable plastic materials produced from biomass and are designed to be degraded by organisms [3]. These substances have been identified has the alternative to fossil fuels, thereby reducing the $\mathrm{CO}_{2}$ emission as well as plastic wastes [1]. A major challenge of largescale production of this bioplastic is the cost of production which has led to the shift towards research on polymer composites and blends with natural polymers [4]. These blends can be processed and 
commercialized quite easily.

Proper incorporation of natural polymers like chitosan, cellulose or starch in LDPE matrix has been proposed to bring about a possible lasting solution to the issue of non-degradable plastics [5]. Chitosan, a natural polymer and the second most abundant biopolymer has drawn attention of researchers because it possesses unique activity of anti-microbial, and good biocompatibility, and biodegradability [6]. Chitosan obtained from the natural polysaccharide called chitin is usually present in the shell of crab, jellyfish, shrimp, coral, ladybug, mushroom, butterfly etc. Crustacean shells are commonly employed as the primary sources of chitosan [7]. The method of deacetylation with the use of excess $\mathrm{NaOH}$ as reagent with water as the solvent are the most used method of producing chitosan.

In recent years, Chitosan nanoparticles has been which can be synthesized from chitosan using several methods such as the ionic gelation method. It has found application in reinforcing and strengthening materials [8], in membranes as tissue engineering materials and for dialysis [9] and in the treatment of waste water to remove toxic metals and dyes [10]. To the best of the authors' knowledge, there are very limited or no studies have reported the application of chitosan nanoparticles as nanofiller in the preparation of biodegradable composite of LDPE.

A major demerit of reinforcing or blending synthetic polymer with natural polymers is the problem of incompatibility, and this is as a result of the hydrophilic natural polymers being immiscible with the synthetic polymers which is hydrophobic in nature [11]. In the findings of Sunilkumar et al. [4] on a study of biodegradation of low-density polyethylene-chitosan composites, observed coalescence and weak interfacial adhesion of chitosan in the unplastisized LDPE matrix resulted because of poor dispersion and tensile strength. Similar work done by Tan [12] on the processing and evaluation of low-density polyethylene/chitosan anti-microbial films also reveals the incompatibility of chitosan-LDPE matrix. Chitosan has microbial inhibition property against a number of well-known organisms. The addition of chitosan nanoparticles is proposed to give a compatible matrix with improved anti-bacterial properties for applications in packaging industries.

Hence, the study focused on improving the biodegradability of LDPE by incorporating chitosan nanoparticles as biodegradable nano filler and improving the biocompatibility of LDPE with the natural polymer by optimizing the amount of a chitosan nanoparticle in the matrix of the biocomposite. This present paper will also investigate the physiochemical, mechanical, morphology, thermal and swelling properties of LDPE/CHNP biocomposites produced by varying the filler's composition in the matrix.

\section{MATERIAls AND Method}

\section{A. Chemicals}

Acetic acid, Xylene and all other chemicals used as well as all apparatus and materials used such as beaker, conical flask, measuring cylinder, round bottom flask, refluxing apparatus, were of analytical grade purchased from Sigma-Aldrich USA. Chitosan nanoparticles used in this study was obtained from blue cab shells and the industrial grade LDPE granules (Indorama Eleme Petrochemicals Limited, Nigeria) purchased from Polyflex Industry limited Sango, Nigeria.

\section{B. Synthesis of Low-Density Polyethylene-Chitosan Nanoparticles Biocomposite}

Low Density Polyethylene-Chitosan Nanoparticles (LDPE/CHNP) biocomposite was synthesized by modification of the method of solvent casting by Sandeep et al. [13] Low density polyethylene (LDPE) pellet was dissolved through reflux heating in $50 \mathrm{ml}$ of xylene and chitosan nanoparticles (CHNP) were also dissolved in $10 \mathrm{ml}$ acetic acid. The two solutions were then mixed in an appropriate proportion (Table I) and thoroughly stirred to form a viscous solution, allowed to cool at room temperature before been spread on a Teflon mould. It was then allowed to dry in a vacuum oven at $35^{\circ} \mathrm{C}$ for all solvent present to evaporate. They were then carefully kept in a moist free environment.

\begin{tabular}{ccc} 
TABLE I: VARIATION OF WEIGHT PERCENT OF CHNP IN THE LDPE/CHNP BIOCOMPOSITE \\
\hline \hline Weight (\%) of CHNP & LDPE $(\mathrm{g})$ & CHNP $(\mathrm{g})$ \\
\hline $0 \%$ (reference) & 5.00 & 0.00 \\
$5 \%$ & 4.75 & 0.25 \\
$10 \%$ & 4.50 & 0.50 \\
$20 \%$ & 4.00 & 1.00 \\
$100 \%$ (reference) & 0.00 & 5.00 \\
\hline \hline
\end{tabular}


European Journal of Advanced Chemistry Research www.ej-social.org

\section{Characterization of the Biocomposite}

\section{1) Physicochemical Properties}

a) Thickness

Digital Vernier caliper was used to determine the thickness of the bio-composites. These were carried out by taking ten different measurements at different points on the bio-composite and the thickness was taken as the average measurement of all.

\section{b) Water Uptake}

Water uptake (WU) was done by following a similar methodology proposed by Chung et al. [14]. The samples of the composite films were cut into size $2 \mathrm{~cm} \times 2 \mathrm{~cm}$ with pre-determined thickness. The weight of the samples was determined after drying them in vacuum desiccators overnight. The samples were then immersed in an air tight bottles containing distilled water and placed in a thermostatically controlled oven. The weight of each samples was taken after the first day (Day 1) by drying the surface of each samples between filter paper and weighed immediately, then returned back into the bottles. The samples were continuously weighed daily until equilibrium swelling was reached. The weighing of each samples were done within 30 seconds so that error as a result of evaporation was negligible. The water uptake was determined using (equation (1)) and was plotted against time to show the relationship graphically.

$$
\% W U=\frac{W_{2}-W_{1}}{W_{1}} \times 100
$$

where $\mathrm{W}_{1}, \mathrm{~W}_{2}$ are the weight of the samples before and after immersion in water respectively.

c) Opacity

The percentage opacity of the biocomposites was determined with the aid of a UV-VIS Spectrophotometer (PerkinElmer, Inc., USA) at $600 \mathrm{~nm}$ by measuring the light transmittance [15]. The samples were cut into sizes $4 \mathrm{~cm} \times 1 \mathrm{~cm}$, then attached to one side of the colorimetric cup while on the other hand, an empty colorimetric cup was used as the control. The following formula was used (equation (2)) to determine the opacity (\%);

$$
\% \text { Opacity }=\frac{A b}{X}
$$

where, $A \mathrm{~b}$ is the absorbance at $600 \mathrm{~nm}$ and $\mathrm{x}$ is the film thickness (mm).

d) Density

The density of the sample films was determined from the weight and dimension of a $2 \times 2 \mathrm{~cm}$ size of the samples cut (equation (3)) [16].

$$
\text { Density }=\frac{M}{A \cdot x}
$$

Density is in $\mathrm{g} / \mathrm{cm}^{3}$ of the sample, $M$ represent the mass $(\mathrm{g})$, ' $\mathrm{x}$ ' represent the thickness and $\mathrm{A}$ is the area $\left(\mathrm{cm}^{2}\right)$.

\section{2) Mechanical Properties}

A Universal Testing Machine having a load cell capacity of 50 KN (Instron Machine-Series 3369, UK) and long travel of $0-550 \mathrm{~nm}$ extensometer was used to determine the mechanical properties of the biocomposites. The samples were cut into $30 \mathrm{~mm}$ by $21 \mathrm{~mm}$ and diameter of $42 \mathrm{~mm}$, and loaded continuously while measurement was taken by a load transducer (load cell) place between the crosshead and the sample. The ASTM D 882-02 standard was followed while carrying out the test.

\section{3) Thermal Properties}

The thermal degradation of the chitosan nanoparticles was examined with the aid of thermogravimetric analyzer TGA-Q500 (TA Instruments, New Castle, USA). The temperature ranges 0-900 ${ }^{\circ} \mathrm{C}$, with the rate of heating set at $10{ }^{\circ} \mathrm{C} \mathrm{m^{-1 }}$ and $60 \mathrm{~cm}^{3} \mathrm{~min}^{-1}$ was maintained for the nitrogen flow to carry out all the analysis.

\section{4) Morphological Properties}

The size and the morphology of LDPE/CHNP biocomposites were examined in Quanta 400 ESEM/EDAX (FEI, USA). A little amount of the prepared samples was vacuum dried and kept on a SEM stub with a double-sided tape at $60 \mathrm{~mA}$ for $5 \mathrm{~min}$ with a sputter. Then, the stub having the sample was put into the Chamber of the SEM. The photomicrograph was taken at an acceleration voltage of $25 \mathrm{KV}$.

5) Crystallinity

Wide-angle X-ray diffraction (XRD) measurement of LDPE/CHNP composite was done with a LabX XRD-6000 (Shimadzu, Japan) X-ray diffractometer with a high speed and high precision vertical 
goniometer. The diffraction spectra were analyzed over a $2 \theta$ range, using $\mathrm{CuK} \alpha \mathrm{Cu} \mathrm{K} \alpha$ radiation $(\lambda=$ $0.154 \mathrm{~nm}$ ) using a scanning rate of $20 / \mathrm{min}$ with a sampling pitch of $0.05^{\circ}$, diffraction angle from $10^{\circ}$ and $80^{\circ}$. The d-spacing was done with the Bragg's equation, $\lambda=2 \mathrm{~d} \sin \theta$.

\section{6) Biological Tests \\ a) Microbial inhibition}

For the microbial inhibition test, agar disk diffusion method was employed [17]. Two gram-positive bacteria (E.coli, and P.aeruginosa) and three gram negative bacterial (S.aureus, P.vulgaris, E.taecalis) were used. For each of the bacterial strain studied, $100 \mu \mathrm{l}$ bacterial suspension using $105 \mathrm{CFU} \mathrm{ml}^{-1}$ dilution was inoculated on Mueller Hinton agar (beef extract, acid hydrolysate of casein, starch). Drigalski loop was used then used to distribute the bacterial suspension uniformly on the surface of the agar in the petri dish. The biocomposite films were cut in $1 \mathrm{~cm} \mathrm{X} 1 \mathrm{~cm}$ and opened to the surface of the agar. Afterwards, they were were incubated for a period of $24 \mathrm{~h}$ at the temperature of $37^{\circ} \mathrm{C}$, after which the measurement of the inhibition diameters was done.

\section{b) Biodegradability Test}

The evidence of colony growth was examined by placing the samples on the prepared mineral salts agar in a Petri dish with no additional carbon source, which was the incubated at $25^{\circ} \mathrm{C}$ for $48 \mathrm{hrs}$. The samples were then examined for colony growth. Biodegradability of the samples has been studied by incubating the films in a medium of Mueller Hinton (beef extract, acid hydrolysate of casein, starch) agar inoculated with Escherichia coli (E. coli) which was then incubated at ambient temperature $\left(25^{\circ} \mathrm{C}\right)$ for 21 days [4]. The Samples were cut $(1.0 \mathrm{~cm}$ by $1.0 \mathrm{~cm})$ and the initial weights before inoculation determined by weighing. The samples were examined for weight loss for 21 days.

The degradation efficiency $(\%)$ and rate $(\mathrm{g} / \mathrm{d})$ were calculated by following the method used in previous research [18] as shown in equation (4) and (5), respectively.

$$
\begin{gathered}
\text { Efficiency }=\frac{W_{F}-W_{I}}{W_{I}} \times 100 \\
\text { Rate }=\frac{W_{L}}{t}
\end{gathered}
$$

where $W_{F} W_{I} W_{L}$ and $t$ represent the final weight $(\mathrm{g})$, initial weight $(\mathrm{g})$, weight loss $(\mathrm{g})$ and time of degradation (days).

\section{Data Analysis}

All experiments were done in triplicate and analyzed by Analysis of Variance (ANOVA).

\section{RESUlTS AND DisCUSSION}

\section{A. Physicochemical Properties of LDPE/Chitosan Nanoparticles Biocomposite}

\section{Thickness}

The result shows an increase in the thickness of the films as the percentage of chitosan nanoparticles increased (Table II). The thickness of the LDPE $(1.532 \mathrm{~mm}$ ) gave the lowest while, the highest thickness value was gotten for CHNP20 with $3.405 \mathrm{~mm}$. This finding is in agreement with observations of Tan [12], on LDPE/Chitosan blend. Though the range of value of thickness varies which could be influenced by preparation method as well as the mould used because these is known to affect final thickness bioplastic film [19]. The increase in thickness with CHNP in the biocomposite could indicate that the bioplastic may have good strength to withstand stress from being torn easily because packaging materials needs some measure of thickness [20].

TABLE II: PHYSICOCHEMICAL PROPERTIES OF THE LDPE/CHNP BIOCOMPOSITES

\begin{tabular}{cccccc}
\hline \multicolumn{7}{c}{ TABLE II: PHYSICOCHEMICAL PROPERTIES OF THE LDPE/CHNP BIOCOMPOSITES } \\
\hline \hline Properties & LDPE & CHNP5 & CHNP10 & CHNP15 & CHNP20 \\
\hline Thickness & $1.532 \pm 0.0020$ & $1.693 \pm 0.2814$ & $2.218 \pm 0.3000$ & $2.83 \pm 0.3014$ & $3.405 \pm 0.4962$ \\
Density & $0.0638 \pm 0.0002$ & $0.0550 \pm 0.004$ & $0.0501 \pm 0.006$ & $0.0497 \pm 0.007$ & $0.0479 \pm 0.011$ \\
Absorbance (at & $1.058 \pm 0.0020$ & $1.1990 \pm 0.0010$ & $1.2340 \pm 0020$ & $1.2513 \pm 0.0013$ & $1.2760 \pm 0.0020$ \\
600nm) & $0.6893 \pm 0.0002$ & $0.7082 \pm 0.0012$ & $0.7564 \pm 0.0005$ & $0.7722 \pm 0.0006$ & $0.7947 \pm 0.0004$ \\
\hline Opacity (\%) & & &
\end{tabular}

Values given are means from triplicates \pm standard deviation.

\section{Opacity}

The wavelength of $600 \mathrm{~nm}$ which is generally employed for comparing film transparency was used [20][22]. The results obtained indicated that LDPE films was less opaque. The opacity of the biocomposite increased as chitosan nanoparticles was blended with LDPE and the increase was more evident when the 
CHNP content increased. The opacity of the pure LDPE increased from 0.6893 to 0.7082 with the addition of $5 \%$ chitosan nanoparticles. A possible observation for this increase in opacity could probably be due to the compactness of the composite film which could have resulted in the closing of the pores [20]. The appearance of CHNP powder is opaque, with yellowish colour. However, due to the Maillard reaction that could occur when the carbonyl group reacts with the amino group in chitosan, the appearance of chitosan turned to a brownish colour [12]. As the chitosan nanoparticles content increased, the colour became more intense and increased the opacity of the films. Also the CHNP dispersed in the LDPE matrix is responsible for the scattering of diffusing light radiation, reducing the amount of light transmitted through the films. The transparency of films is also affected by the thickness and surface properties of the films. It can be observed from Table II that there was a progressive increase in thickness of the films as the CHNP content increased, which resulted in lesser transmittance of light through the films. The result of the opacity gives an indication that the addition of CHNP to LDPE improved the light hindrance property. Hence, the application of this biocomposite film for packaging of materials that could be damage by light will have longer shelf life as it has high opacity. For example, if foods such as fruits, vegetable and fruits which could undergo lipid oxidation is packaged with CHNP15 or CHNP20 their shelf life could be prolonged.

\section{Water uptake}

The water uptake by LDPE/CHNP biocomposites is given in Fig. 1. The result shows that there was increase in water uptake capacity as the amount of CHNP in the biocomposites increase. This could possibly be as a result of the strong interaction of amino and hydroxyl groups of chitosan with water molecules [23], [24]. The uniform distributed chitosan nanoparticle in the matrix has high surface area, therefore leading to the high water absorption property of the biocomposite. Water uptakes in biocomposite are possibly due to the presence of chitosan particles at the surface or close to the surface that could possibly absorb moisture much faster than those at the interior part of the matrix. The presence of CHNP affects the water diffusion as observed in Table III. Since CHNP is hydrophilic with high affinity for water molecules [4]. Hence, the findings from this experiment is in line with the increase in water uptake as the amount of chitosan nanoparticles present in the biocomposite increased.

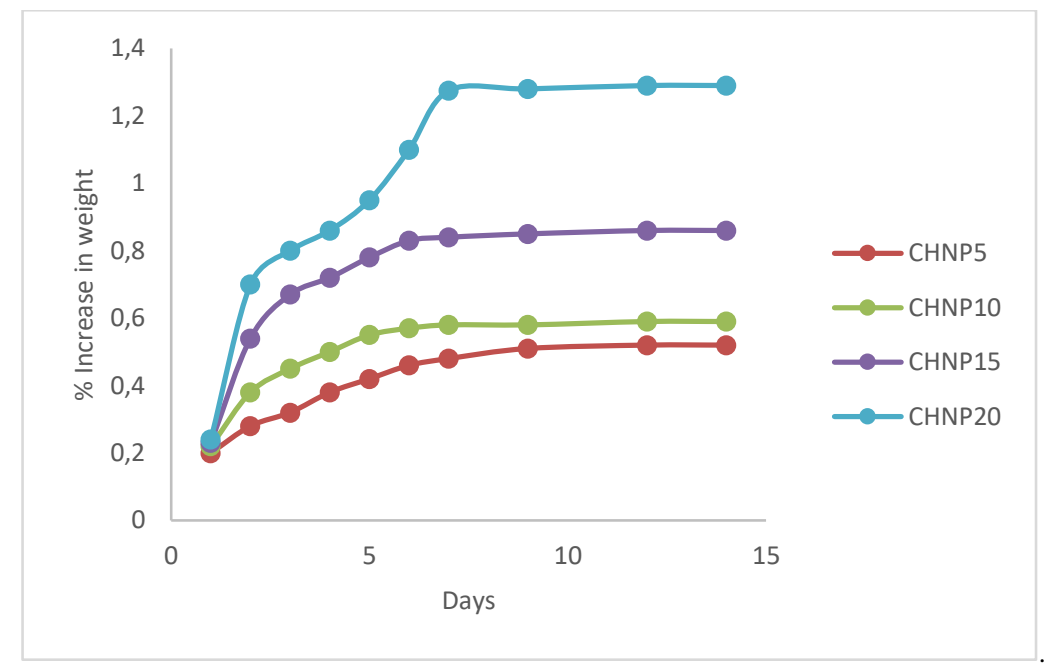

Fig. 1. Water uptake property of the LDPE/CHNP biocomposites.

TABLE III: MECHANICAL PROPERTIES OF THE LDPE/CHNP BIOCOMPOSITES

\begin{tabular}{ccccc}
\hline \hline Samples & Elongation at Break & $\begin{array}{c}\text { [aximum Tensile strength } \\
(\mathrm{mPA})\end{array}$ & $\begin{array}{c}\text { Tensile strain } \\
(\text { Standard })(\mathrm{mm})\end{array}$ & $\begin{array}{c}\text { Young Modulus } \\
(\mathrm{E})\end{array}$ \\
\hline LDPE & $19.560 \pm 0.6040$ & $0.41453 \pm 0.0002$ & $0.19560 \pm 0.0042$ & $2.1193 \pm 0.2020$ \\
CHNP5 & $18.504 \pm 0.5200$ & $0.61468 \pm 0.0003$ & $0.18504 \pm 0.0040$ & $3.3219 \pm 0.4020$ \\
CHNP10 & $13.556 \pm 0.3400$ & $1.55538 \pm 0.0020$ & $0.13556 \pm 0.0012$ & $11.4737 \pm 0.6012$ \\
CHNP15 & $15.222 \pm 0.3700$ & $3.51579 \pm 0.2200$ & $0.15222 \pm 0.0020$ & $23.0968 \pm 0.8020$ \\
CHNP20 & $19.111 \pm 0.5800$ & $3.24006 \pm 0.2000$ & $0.19111 \pm 0.0030$ & $16.9539 \pm 0.7020$ \\
\hline \hline
\end{tabular}

Values given are the means of the triplicates \pm standard deviation.

From previous studies, hydrophilic composite blend with high water absorptivity is more susceptible to microbial attack than composites of hydrophobic nature [25]. Therefore, the hydrophilic nature of this biocomposite is most likely to make it susceptible to microbial attack, making it much easier for microorganism to have access to interior part of the biocomposite with water as the medium. This further implies that there is a possibility that the samples with more percentage of CHNP would be more biodegradable. 


\section{B. Mechanical Properties}

The result of the mechanical properties shows that the tensile properties of CHNP5 to CHNP15 improved gradually and reduction was observed from CNNP15 to CHNP20. The increased in mechanical properties with the addition of CHNP was probably due to more interaction between the matrix as well as compatibility of CHNP with LDPE up to $15 \%$ weight of the CHNP. The tensile strength of LDPE $0.41 \mathrm{MPa}$ was improved progressively: 0.61, 1.55, 3.52, respectively for CHNP5, to, CHNP15, and a reduction (3.52 to 3.24, ) was observed at CHNP20 biocomposite (Table III). This observation indicates that the more CHNP added to LDPE results in an increase in the elongation resistance of LDPE up to $15 \%$ weight of CHNP which could indicate good shearing strength. Further increase in above 15\% must have resulted in the aggregation of CHNP within the biocomposite, which led to the loss of homogeneity of the structure causing a reduction in the tensile strength [26]. The measure of rigidity, young modulus followed similar pattern as tensile strength. With values of 3.33 (CHNP5), 11.47 (CHNP10) and 23.10 (CHNP15), 16.95 (CHNP20), against $2.12 \mathrm{MPa}$ (LDPE). The increase in strength of the biocomposite could be ascribed to the good interfacial bond of LDPE and chitosan nanoparticles due to the compatibility of the composite [26] The result of the composite formed in the work of Sunilkumar et al. [4] revealed that the mechanical properties of unplastized composite of LDPE/Chitosan reduced with increasing content of chitosan in the matrix which was due to their weak interfacial adhesion which is responsible for the poor tensile strength. But the increase in mechanical property observed in the LDPE/CHNP biocomposite up to $15 \%$ weight o CHNP in this work could be ascribed to the particles size of CHNP which must have been responsible for strong bond with the LDPE since agglomeration is lessened and the CHNP molecules causes a reinforcing effect on the biocomposite matrix.

\section{FTIR Analysis of LDPE/CHNP Biocomposite}

FTIR spectra of LDPE and LDPE/CHNP films was analysed in the wave number range of 4000-350 (Fig. 2 and Fig. 3-6, respectively). LDPE showed accentuated peaks at $2914-2847 \mathrm{~cm}^{-1}$ for (CH) stretching. The peaks of $719 \mathrm{~cm}^{-1}$ and $1468 \mathrm{~cm}^{-1}$ represented the skeletal vibrations of $\mathrm{CH}_{2}$ (Fig. 2). The absorption peaks of chitosan at $3464-3459 \mathrm{~cm}^{-1}$ for amino groups and $\mathrm{OH}$, inter and intra molecular hydrogen bonding is seen in the spectrum of the LDPE/CHNP [28]. Peaks around in the spectra of 1107 and $1390 \mathrm{~cm}^{-1}$ seen can be accredited to saccharide structure. Peaks around in the spectra of $1107 \mathrm{~cm}^{-1}$ corresponds to the vibration of COC groups in chitosan since chitosan also contains the functional group of the aliphatic ethers. The peak around $1643 \mathrm{~cm}^{-1}$ and $1551 \mathrm{~cm}^{-1}$ are due to carbonyl groups and represent acetylated amino group of chitin, which means incomplete deacetylation [4].

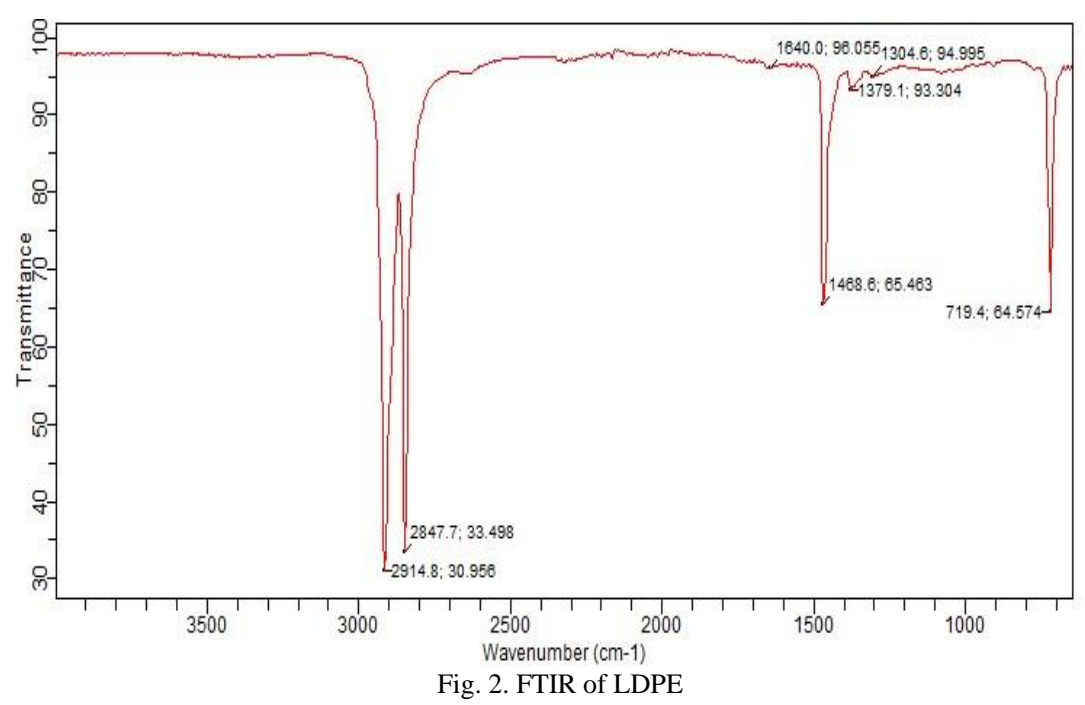

In case of CHNP5 film, absorption spectra (Fig. 3) between 3750 and $3000 \mathrm{~cm}^{-1}$ showed widening. The LDPE film shows a peak at $3450-2932 \mathrm{~cm}^{-1}$, the $\mathrm{CH}_{3}$ bending seen at $1643 \mathrm{~cm}^{-1}$ is almost similar to that seen in CHNP5 spectra. The spectra of LDPE/CHNP increased in broadness and intensity as the percentage of chitosan nanoparticles increased from $5 \%$ to $20 \%$ between 3750 and $3000 \mathrm{~cm}^{-1}$ probably due to the increase in CHNP content. Similarly, skeletal vibration peak of $720 \mathrm{~cm}^{-1}$ became less intense as the CHNP concentration increased. As CHNP content increased, there was also an observed increase in the absorption peaks at $1107 \mathrm{~cm}^{-1}$, corresponding to the saccharide structure found in CHNP. Wanchoo and Sharma [29] proposes that the interactions that takes place between two or more chemical groups on different polymers theoretically should result in a shift of the peak positions of the groups present. This study is in agreement with literature as there were observed shift in peak position of the participating groups and the shift in peaks could clearly be an indication that a sort of interaction exist between the matrix and the filler. The 
interactions may as well be as a result of the similar geometrical and chemical linear structure of both CHNP and LDPE in the composite films.

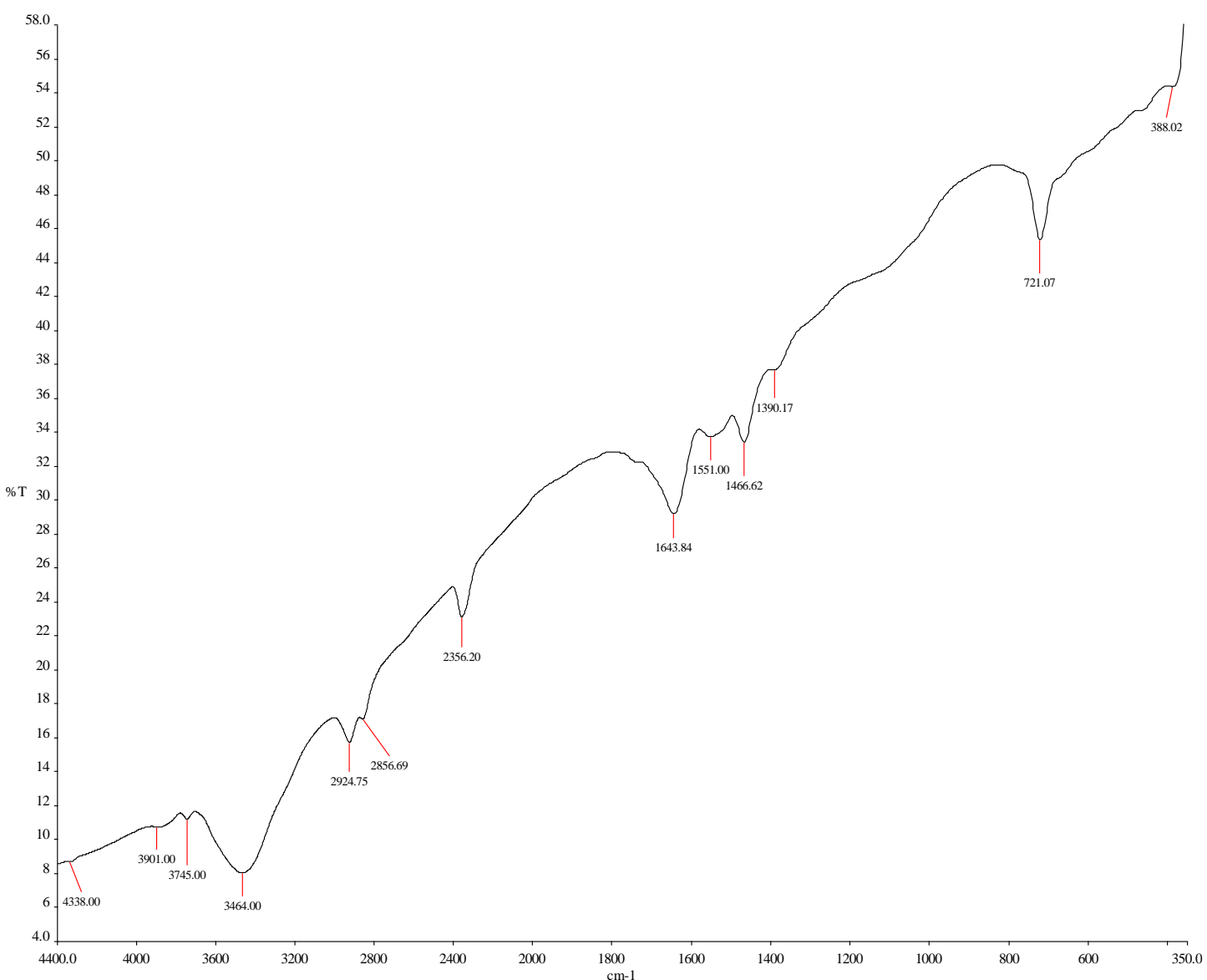

Fig. 3. FTIR of CHNP5.

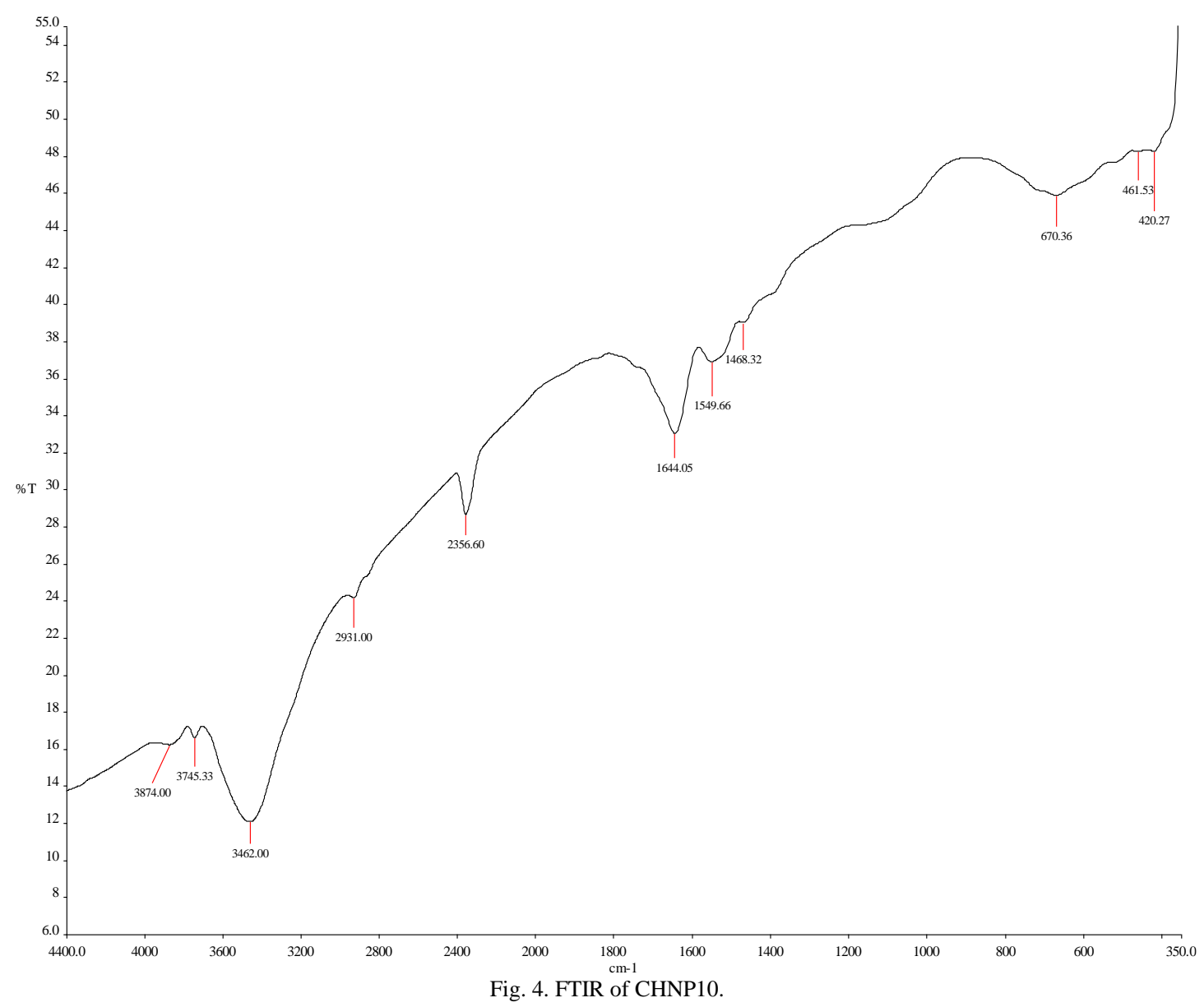


European Journal of Advanced Chemistry Research www.ej-social.org

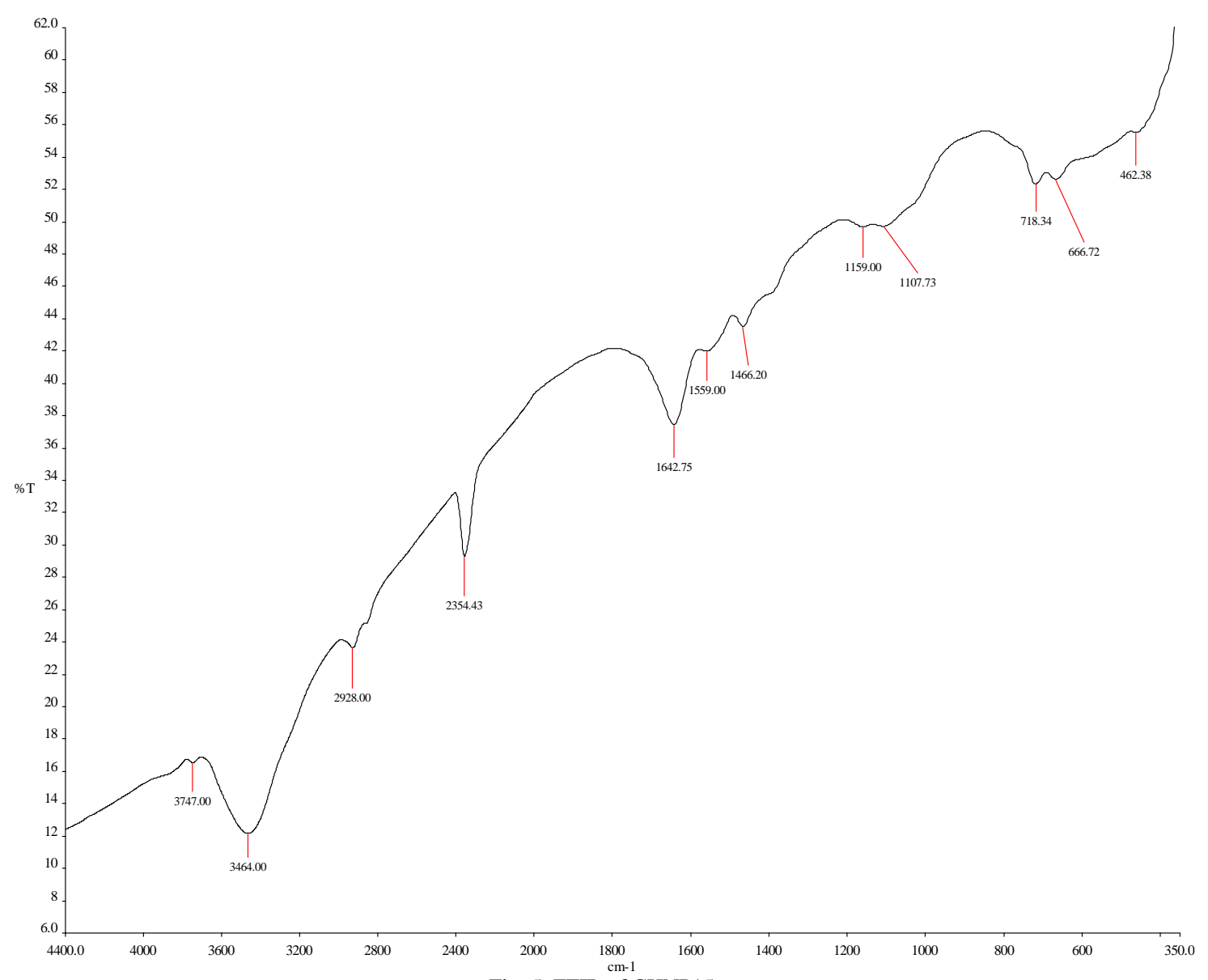

Fig. 5. FTIR of CHNP15.

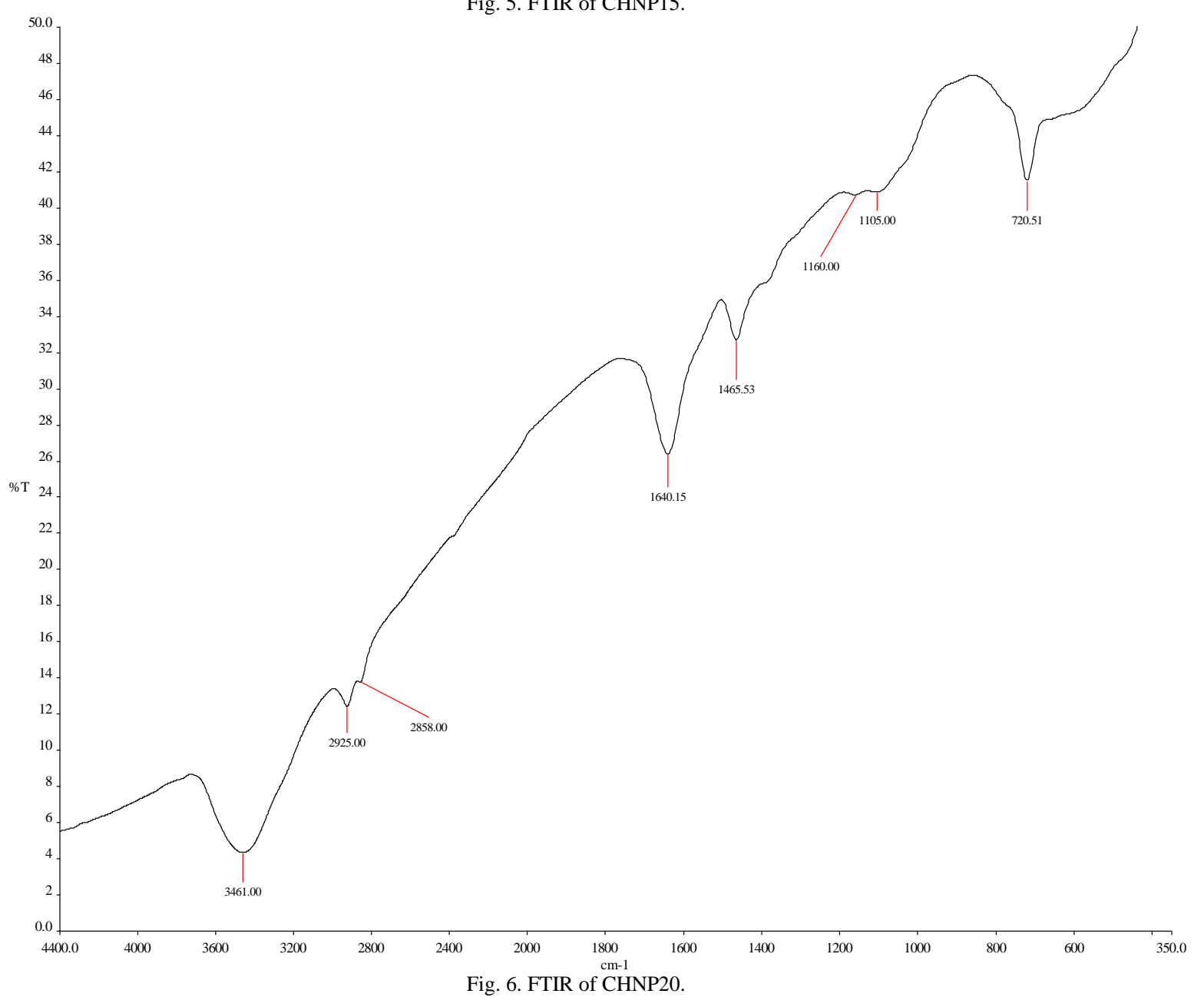




\section{Morphology of LDPE/CHNP Biocomposite}

The scanning electron microscope (SEM) images of the biocomposites showed relatively in uniform morphology which got better as the content of the CHNP increased in the matrix from CHNP5 to CHNP15 while a sharp drop in the uniformity of the morphology of CHNP20 was observed (Fig. 7). This observation in the micrograph images obtained for this samples, supports the result obtained for the mechanical properties (tensile strength and young modulus) with similar progression for the different compositions of the biocomposites with improvement of their properties from CHNP5 to CHNP15 and a reduction observed CHNP15 to CHNP20. Similar observations were noted in the findings reported in the research work of Abreu et al. [30] on new polyolefin films development using nanoclays. Sunilkumar et al. [4] in their research on Low density polyethylene-chitosan composites, also had similar result with $10 \%$ of chitosan in the matrix being their optimum concentration having both the best mechanical property and uniformity in micrograph image. Therefore, the observation in the morphology of the biocomposite as supported by our findings from the mechanical property gives an indication that the optimum concentration needed to form a good biocomposite of CHNP with LDPE is $15 \%$ weight percent of CHNP.

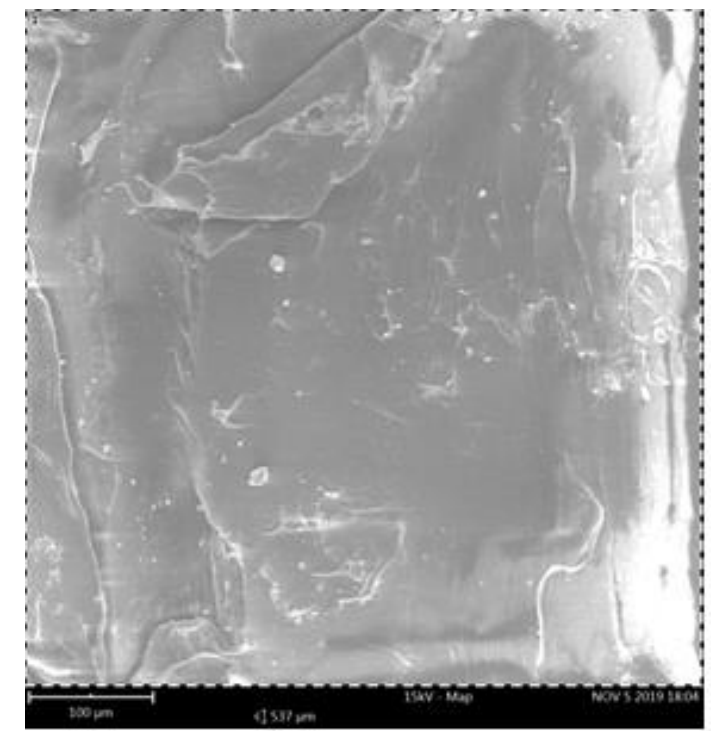

CHNP5

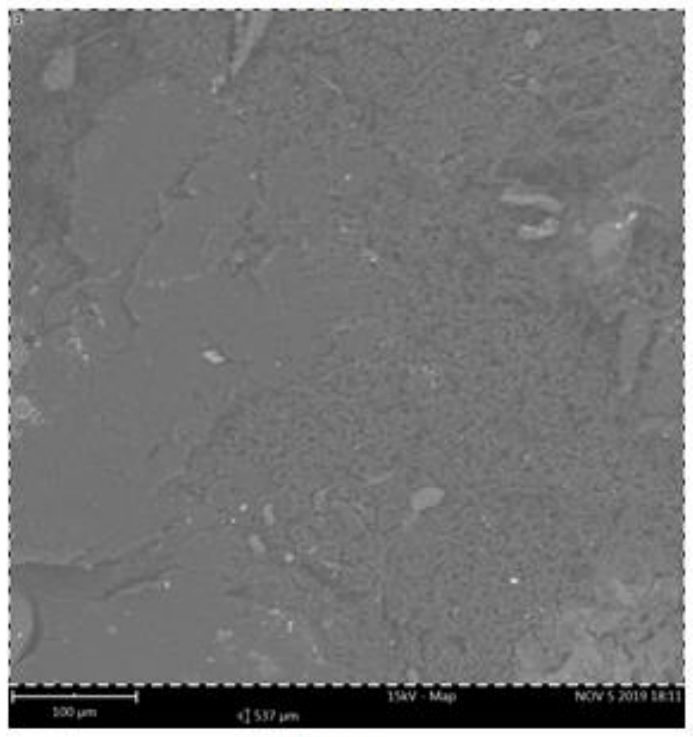

CHNP15

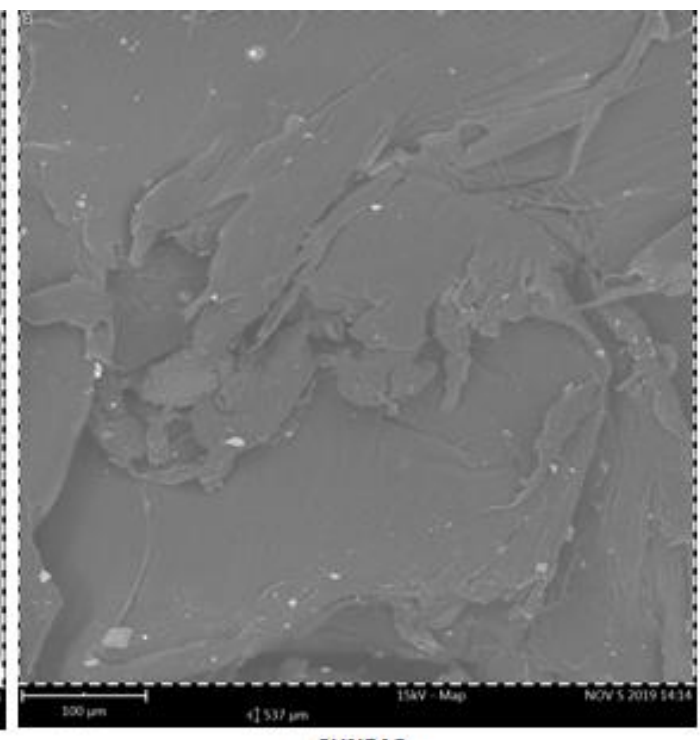

CHNP10

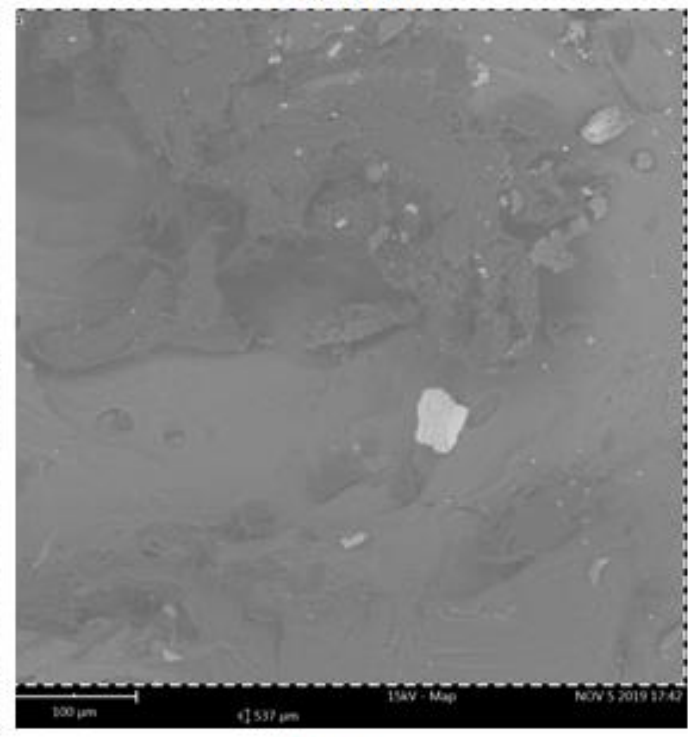

CHNP20

Fig. 7. SEM analysis of the Biocomposites (CHNP5, CHNP10, CHNP15, CHNP20).

\section{E. Thermogravimetric Analysis of LDPE/CHNP Biocomposite}

The thermogravimetric spectrum of LDPE/CHNP is shown in Fig. 8, and the degradation followed three major stages. Similar result was observed in other researches [31], [32]. The first stage of weight loss $\left(100{ }^{\circ} \mathrm{C}\right)$ was due to water loss from evaporation, which was followed by the weight loss between 200 to $300{ }^{\circ} \mathrm{C}$, and then the third stage at temperature above $400^{\circ} \mathrm{C}$ which could be associated with the dehydration of the polysaccharide rings, decomposition and depolymerization of the CHNP molecules. The final stage of temperature degradation could be as a result of the arrangement of polymer chains base on their degree of polymerization which gives priorities to interaction that exist in the composite [4]. 


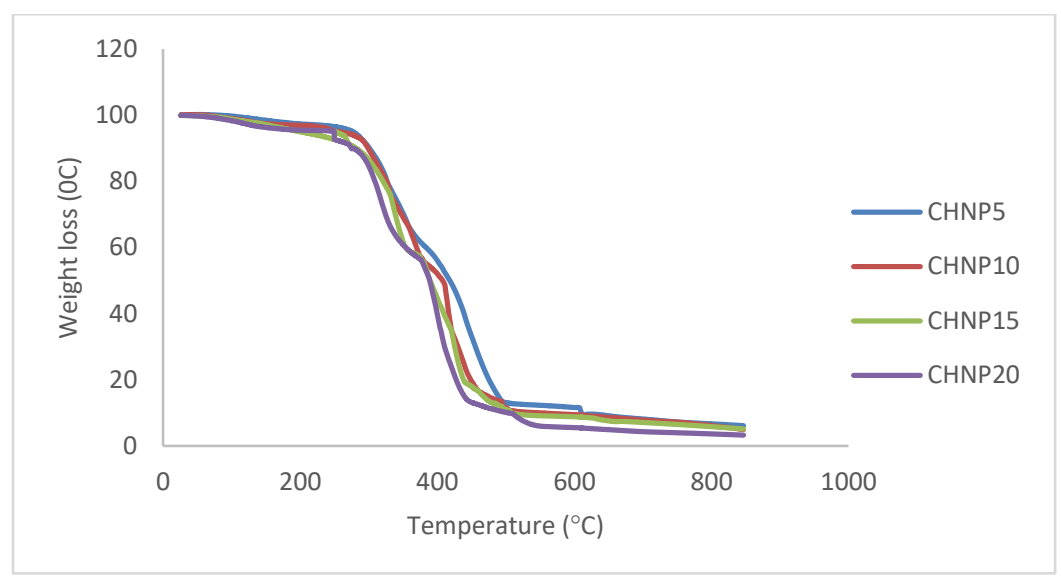

Fig. 8. TGA analysis of the LDPE/CHNP biocomposites

At $100{ }^{\circ} \mathrm{C}$, the TGA curve showed loss of sample weight (downward trend) from $100 \%$ to $90 \%$. A possible explanation to this observation could be moisture loss with temperature increase. With further increase in the temperature to $300{ }^{\circ} \mathrm{C}$ reduced the weight of the samples by another $10 \%$. The sample had a drastic reduction in weight at the temperatures between $300{ }^{\circ} \mathrm{C}$ to $650{ }^{\circ} \mathrm{C}$ where about $50 \%$ of the total mass at the samples were observed to be loss in this range of temperatures. The drastic weight loss might be from depolymerisation and loss of $\mathrm{NH}_{2}$ and $\mathrm{CH}_{2} \mathrm{OH}$ moieties [33]. The last stage of weight loss which occurred between $650{ }^{\circ} \mathrm{C}$ and $900{ }^{\circ} \mathrm{C}$, (about 5\%) bringing the total weight loss to $75 \%$. With this observation in the weight loss in the biocomposites with temperature it can be deduced that LDPE/CHNP can be applied for wastewater treatment at temperatures not more than $200^{\circ} \mathrm{C}$ with no significant effect on the structure.

\section{F. XRD Analysis of LDPE/CHNP Biocomposite}

The original crystalline peak of chitosan nanoparticles seen at $2 \Theta=16^{\circ}$ was no longer apparent in all the biocomposites (Fig. 9). Similar observations were noted when chitosan was blended with poly(L-lactide) (PLLA) and poly(DL-lactide) (PDLLA) [34]. The peak observed at $25^{\circ}$ in the biocomposite could be attributed to the diffraction peak of chitosan nanoparticles at $2 \Theta=24^{\circ}$ which appeared to have merged with the LDPE diffraction peak (which has been widely reported be seen at $2 \Theta=21^{\circ}$ ) due to the sharp intensity of the LDPE crystalline region [11]. As the diffraction patterns of the LDPE/CHNP biocomposites were not the direct superposition of the individual components, it could be deduced from the results that there was miscibility and LDPE and chitosan nanoparticles had formed a partially miscible structure.
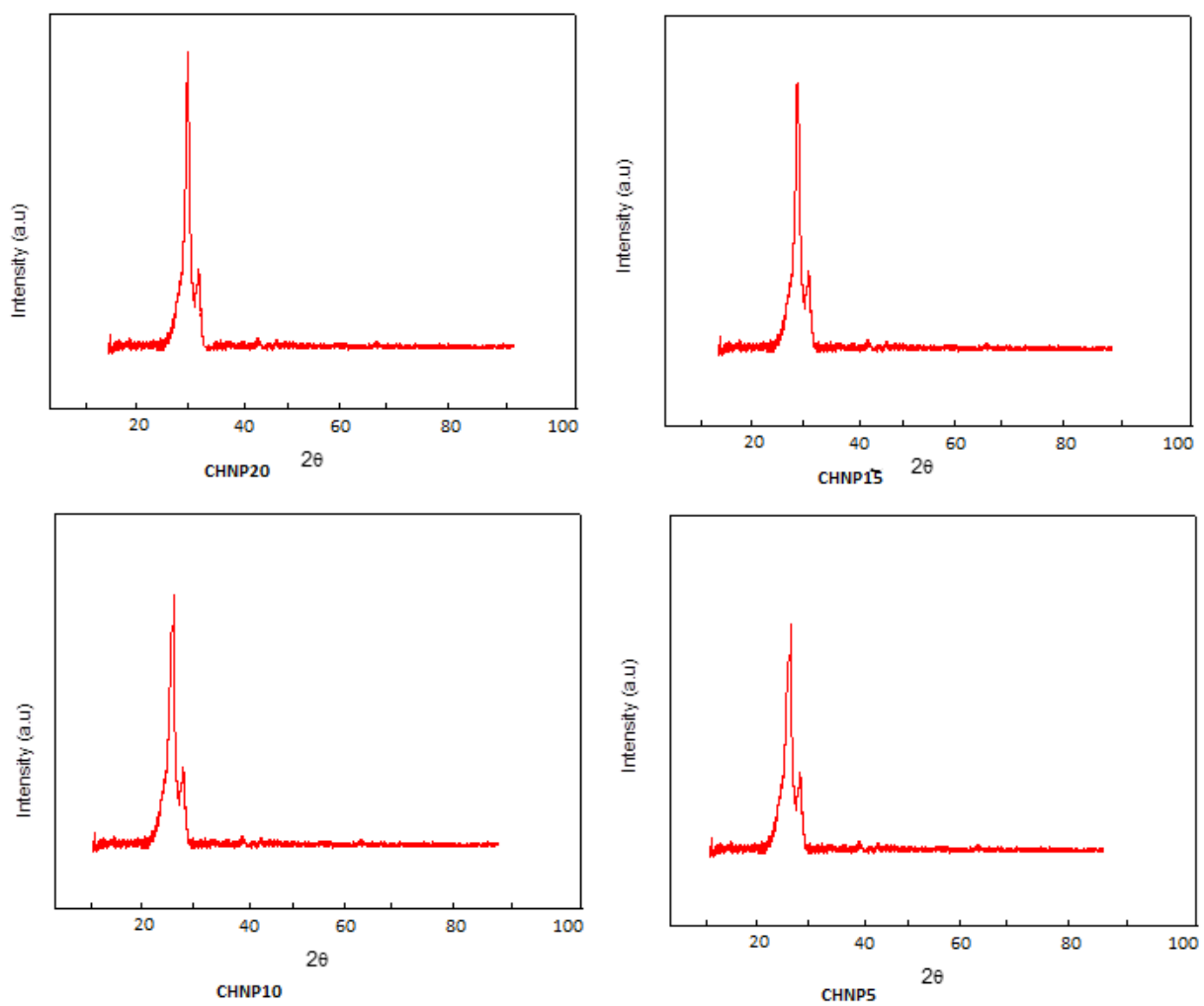

Fig. 9. XRD of the LDPE/CHNP biocomposites. 


\section{G. Antimicrobial Activities of the Biocomposites}

In the test for antimicrobial activity of all the composites from CHNP5 to CHNP20, effective inhibition of Gram-negative and Gram-positive bacteria strain with increasing activities as the percentage of the CHNP increased (Fig. 10). The results reveals that the diameter of inhibition zone of CHPN20 was the largest with $32 \mathrm{~mm}$ from the sample in P. eruginosa and the least was observed in CHNP5 with 10mm from the sample in E. coli, even though it showed significant inhibition compared to the (LDPE) negative control.

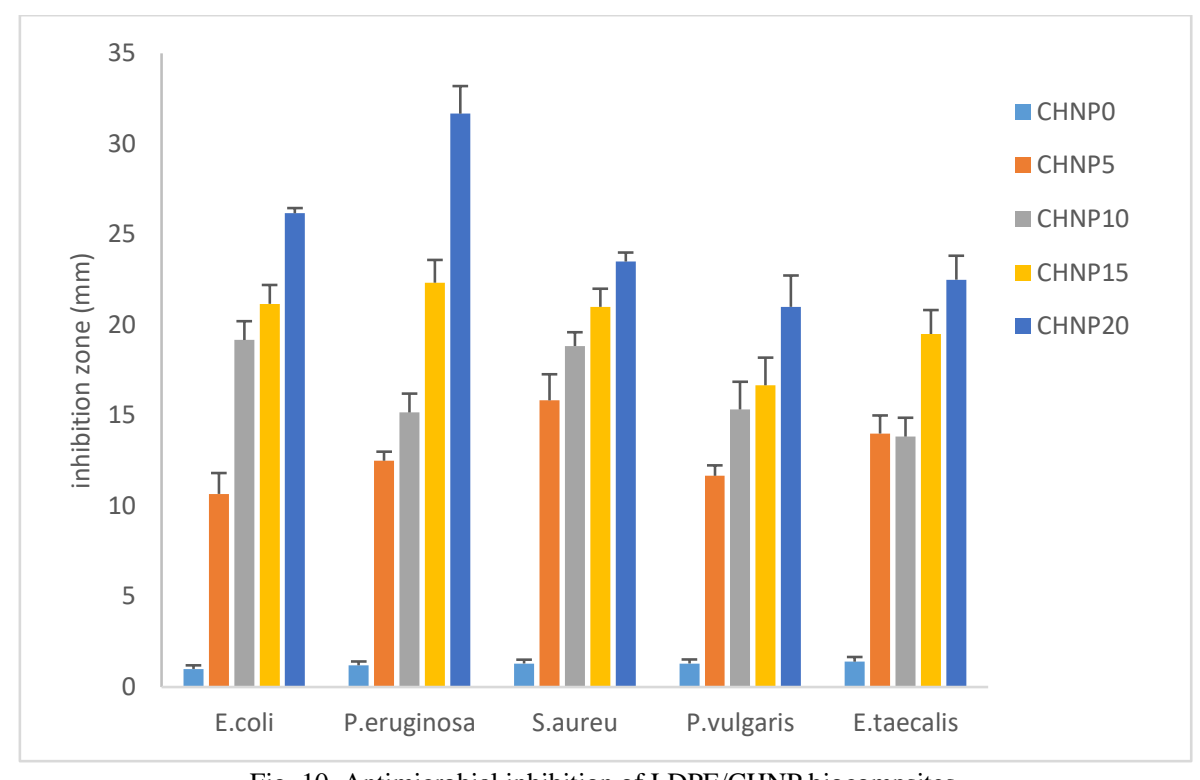

Fig. 10. Antimicrobial inhibition of LDPE/CHNP biocompsites.

The result of this experiment is supported by the work done by Bhawna et al. [35] on the physicochemical, antioxidant antimicrobial and properties of chitosan/TEMPO biocomposite prepared for packaging application where all chitosan/TEMPO-CNFs films revealed they have good antimicrobial property on Gram-negative and Gram-positive bacteria; the films with different chitosan/TEMPOCNFs compositions showed complete inhibition for all three kinds of bacteria used. Also, the result in this study is consistent with the work of Chatchai et al. [36] on the AgCB/PBS Composite System where increase in antimicrobial activities was seen in the biocomposites as the percentage of the nanosilver-coated carbon black $(\mathrm{AgCB})$ increased in the composite.

Films with higher concentration of CHNP showed excellent properties of oxygen barrier [37]. The antimicrobial property of the biocomposites is improved by this property and results in the limitation of their aerobic spore germination. Hence, the efficient inactivation of bacterial with direct contact with the composites could imply that such films will find useful application in packaging of several food products.

\section{H. Microbial Growth, Surface Adhesion and Biodegradability of the LDPE/CHNP Biocomposite}

The growth of microorganism (E. coli) after 7 days of incubation was clearly visible on the biocomposites as shown in Fig. 11. Notably, CHNP in the matrix up to $20 \mathrm{wt}$ \% (CHNP20) showed an obvious microbial growth. E. coli colony growth was seen to increase as more CHNP content was present, which suggest that $E$. coli could have attacked the chitosan particles on the surface of LDPE film. This attack could have weakened the polymer matrix thereby increasing the film's surface volume ratio, permeability and hydrophilicity [4]. On the other hand, there was reduction in the colony of the microorganism in the medium with LDPE as the carbon source. This may probably be due to the microbial inhibition behavior which is integrally associated with LDPE. The LDPE backbone is made up of carbon-carbon linkage and it is resistant to microorganism attacks [4].

To know the biodegradability of the biocomposites the weight of the samples was taken after every 7 days for 21 days of incubation and variation in the weight loss (\%) of samples were observed as shown in Fig. 12.

An observed increase in weight loss of the samples was corresponding to the CHNP content in the samples which agrees with observed increased in microbial attack on the biocomposites with higher percentage of chitosan nanoparticles. 


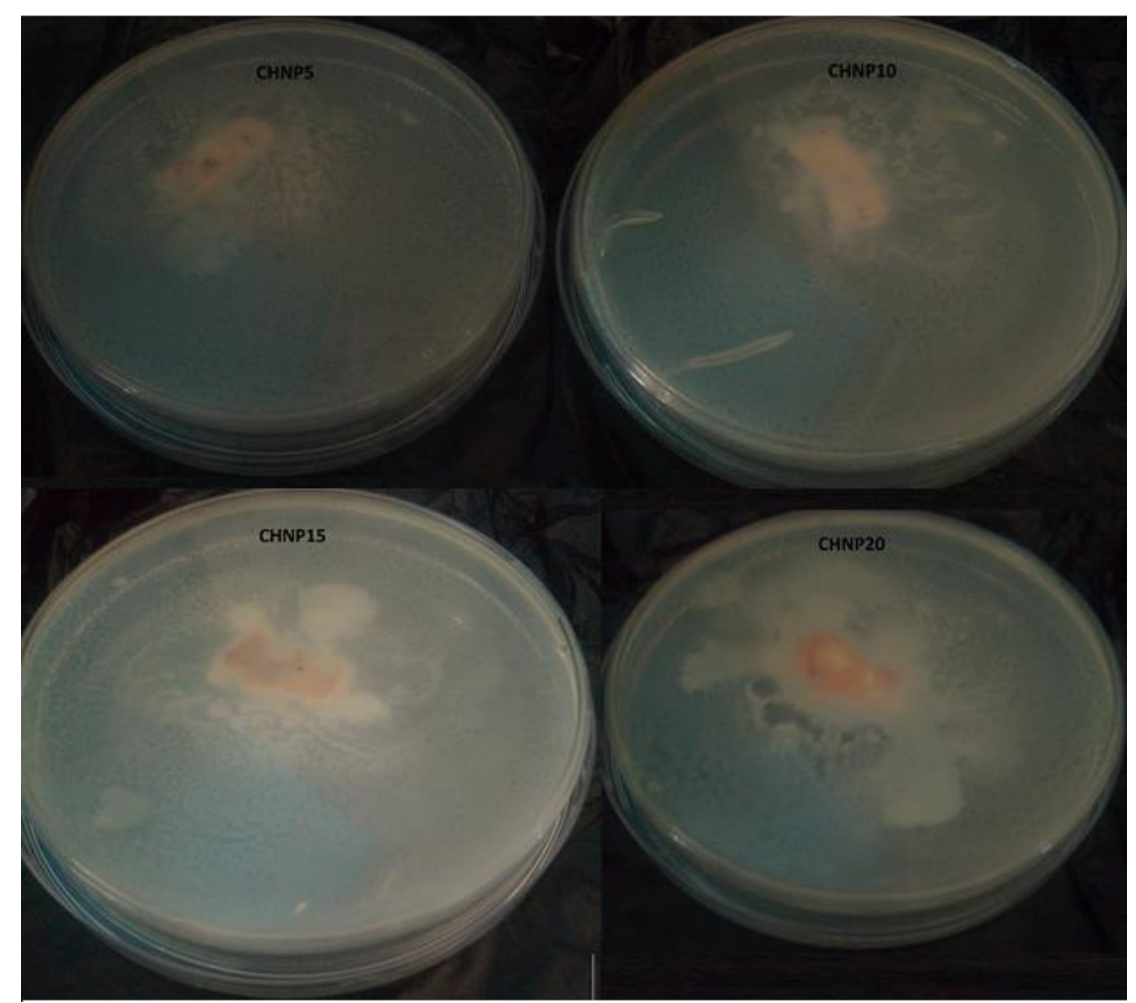

Fig. 11. Surface adhesion and Microbial growth on the Biocomposites.

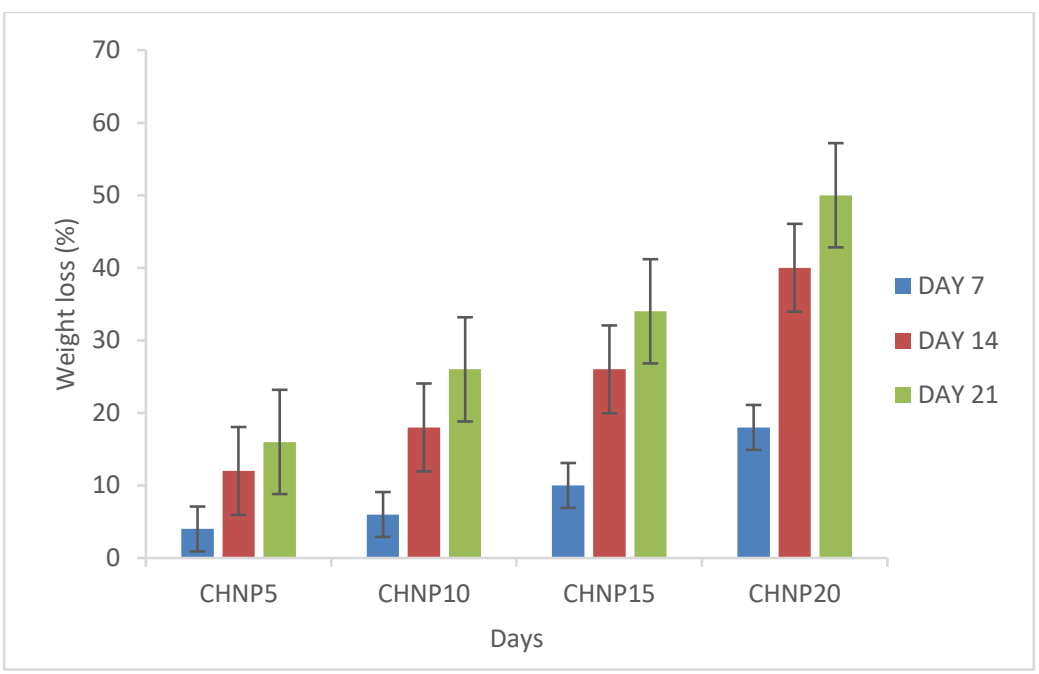

Fig. 12. Percentage Weight loss of LDPE/CHNP after 21 days.

The sample containing the $20 \% \mathrm{w} / \mathrm{w}$ CHNP (CHNP20) had the highest degradation efficiency of $50 \%$ and degradation rate of $0.12 \mathrm{~g} /$ days after 21 days. While the sample containing the $5 \% \mathrm{w} / \mathrm{w}$ CHNP (CHNP5) had the least degradation efficiency of $16 \%$ and degradation rate of $0.038 \mathrm{~g} /$ days after 21 days as shown in Table IV.

TABLE IV: DEGRADATION EFFICIENCY AND DEGRADATION RATE OF THE LDPE/CHNP BIOCOMPOSITES AFTER 21 DAYS

\begin{tabular}{ccc}
\hline \hline Samples & Degradation Efficiency $(\%)$ & Degradation Rate $(\mathrm{g} /$ day $)$ \\
\hline CHNP5 & $16.0 \pm 0.10$ & $0.0381 \pm 0.0019$ \\
CHNP10 & $26.2 \pm 0.15$ & $0.0619 \pm 0.0031$ \\
CHNP15 & $34.1 \pm 0.06$ & $0.0810 \pm 0.0037$ \\
CHNP20 & $50.0 \pm 0.20$ & $0.1190 \pm 0.0011$ \\
\hline \hline
\end{tabular}

Values presented are means of triplicates \pm standard deviation.

According to Tharanathan [38], the biodegradation of a polymer involves several stages like the attachment of the microorganisms to the polymer's surface, microorganism growth, the use of the polymer as the carbon source and primary, then the ultimate degradation of the polymer. These stages have been observed from the result of this experience and this suggest to us the biocomposite of LDPE and CHNP are potential source of biodegradable polymers that could be more susceptible to microbial attack thereby increasing the rate at which they are removed from the environment. 


\section{CONCLUSION}

A Nano derivative of a biodegradable natural polymer, chitosan was incorporated into synthetic polymer LDPE through solvent casting method. The LDPE/CHNP exhibited good compatibility due to the nanoparticle size of chitosan being able to act as filler for LDPE. Physiochemical, thermal, and microbial inhibition rate has been seen to increase with increase in CHNP content in the prepared biocomposite. The result of the biodegradation study showed that the degradation efficiency and rate increased in chitosan nanoparticles loading with $20 \%$ loading (CHNP20) having the maximum degradation efficiency of $50 \%$ and degradation rate $0.12 \mathrm{~g} /$ day after 21 days. The mechanical study showed that the elastic modulus and tensile strength increased with increasing loading of chitosan nanoparticles. The improved mechanical properties have been attributed to the compatibility of the composite. Furthermore, LDPE/CHNP biocomposite film with $15 \%$ chitosan nanoparticles (CHNP15) showed maximum elastic modulus and tensile strength, as well as the best dispersion of particles as revealed by the morphology of the film. The biocomposite film prepared has proved to be degradable, having antimicrobial properties, thereby it could act as an eco-friendly alternative to conventional non-degradable plastics and could be applied in food packaging, fuel cell and wastewater treatment.

\section{ACKNOWLEDGMENT}

We are greatly thankful to the department of Chemistry, Federal University of Technology for making all necessary facilities available for the successful completion of this research work.

\section{CONFLICT OF INTEREST}

The authors declare that they have no known competing financial interests or personal relationships that could have appeared to influence the work reported in this paper

\section{REFERENCES}

[1] Sushmitha B. S., Vanitha K. P., Rangaswamy B. E. Bioplastics - A Review. International Journal of Modern Trends in Engineering and Research (IJMTER), 2016;3(4): 411-413.

[2] Kim M., Lee S. Characteristics of crosslinked potato starch and starch-filled linear low- density polyethylene films. Journal of Carbohydrate Polymer, 2002;50: 331-337.

[3] Dharini S., Mamta, S. Biodegradable Polyethylene Bags. Institute of Technology, Nirma University, Ahmedabad, 2011;8(1): $382-481$.

[4] Sunilkumar M., Francis T., Sujith A. Low density polyethylene-chitosan composites: A study based on biodegradation. Chemical Engineering Journal, 2012;204-206: 114-124.

[5] Corre D. B. Starch nanoparticles: a review. Journal of Biomacromolecules, 2010;11: 1139.

[6] Hu S. G., Jou C. H., Yang M. C. Protein adsorption, fibroblast activity and antibacterial properties of poly (3-hydroxybutyric acid-co-3-hydroxyvaleric acid) grafted with chitosan and chitooligosaccharide after immobilized with hyaluronic acid. Journal of Biomaterials, 2003;24: 2685-2693.

[7] Shahidi F., Abuzaytoun R. Chitin, chitosan, and co products: chemistry, production, applications, and health effects. Journal of Advance Food Nutrition. Resources, 2005;4:93-135.

[8] Rinaudo M. (2009). Chitin and chitosan Properties and applications. Progress in Polymer Science. 31: $603-632$.

[9] Martino A. D., Sittinger M., Risbud M. V. Chitosan: A versatile biopolymer for orthopaedic tissue engineering. Journals of Biomaterials, 2005;5983-5990.

[10] Yeşim S. A, Başak G. Removal of Methyl Red, a cationic dye, Acid Blue 113, an anionic dye, from wastewaters using chitin and chitosan: influence of copper ions. Journal of Desalination and Water Treatment, 2017: 73: 289-300.

[11] Souza B.W., Cerqueira M. A., Martins J. T., Casariego A., Teixeira J. A., Vicente A. A. Influence of electric fields on the structure of chitosan edible coatings. Journal of Food Hydrocolloids, 2010;24: 330-335.

[12] Tan Y. M. Processing and evaluation of Low density polyethylene/Chitosan Antimicrobial films. Doctor of Philosophy Thesis. National University of Singapore, 2016.

[13] Sandeep S. L., Madhu K.D., Viveka S., Nagaraja G. K. Preparation and Properties of Biodegradable Film Composites Using Modified Cellulose Fibre-Reinforced with PVA. International Scholarly Research Network ISRN Polymer Science, 2012. ID 154314:1-8. doi:10.5402/2012/154314.

[14] Chung Y. C., Chen C. Y. Antibacterial characteristics and activity of acid-soluble chitosan. Journal of Bioresource Technology, 2008;99:2806-2814.

[15] Tunç S., Duman O. Preparation and characterization of biodegradable methyl cellulose/montmorillonite nanocomposite films. Application of Clay Science, 2010;48 (3): 414-424.

[16] Salgado P. R., Molina S. E., Petruccelli S., Mauri A. N. Biodegradable sunflower protein films naturally activated with antioxidant compounds. Journal of Food Hydrocolloids, 2010;24 (5): 525-533.

[17] Balouiri M., Sadiki M., Ibnsouda S. K. Methods for in vitro evaluating antimicrobial activity: A review. Journal of Pharmaceutical Analysis, 2016;6: 71-79.

[18] Liang J. Z. The elastic behaviour during capillary extrusion of LDPE/LLDPE blend melts. Journal of Polymer Testing, 2002;21: 69-74.

[19] Abd E. A., Hesham M., Ahmed M. Y. Antimicrobial low-density polyethylene/low-density polyethylene-grafted acrylic acid biocomposites based on rice bran with tea tree oil for food packaging applications. Journal of Thermoplastic Composite Materials, 2020:1-19. DOI: 10.1177/0892705720925140.

[20] Oluwasina O. O., Temitayo F., Oluwasegun J., Wahab, Nosa B. I. Enhancement of Physical and Mechanical Properties of Dioscorea Dumetorum Starch Films with Dialdehyde Starch Solution, 2017. doi: [10.1002/star.201700148]. 
[21] Fang Y., Tung M. A., Britt I. J., Yada S., Dalgleish D. G. Tensile and Barrier Properties of Edible Films Made from Whey Proteins. Journal of Food Science, 2002;67: 188-193.

[22] Zhang Y., Han J. H. Plasticization of Pea Starch Films with Monosaccharides and Polyols. Journal of Food Science, 2006;71: 253-261.

[23] Cervera M. F., Karjalainen M., Airaksinen S., Rantanen J., Krogars K. J., Heinamaki A. I., Colarte J. Y. Physical stability and moisture sorption of aqueous chitosan-amylose starch films plasticized with polyols. European Journal of Pharmaceuticals and Biopharmaceuticals, 2004;58: 69-76.

[24] Mali S., Sakanaka L. S., Yamashita F., Grossmann M. V. Water sorption and mechanical properties of cassava starch films and their relation to plasticizing effect. Journal of Carbohydrate Polymer, 2005;60: 283.

[25] Chuayjuljit S., Hosililak S., Athisart A. Thermoplastic cassava starch/sorbitolmodified montmorillonite nanocomposites blended with low density polyethylene: properties and biodegradability study. Journal of Matals, Materials and Minrals, 2009;19: 5965.

[26] Omer B. M., Ertan A., Gulsen A. E. Electrical, optical and mechanical properties of chitosan biocomposites, Journal of Composite Materials, 2019;0(0):1-14. DOI: 10.1177/0021998319883916.

[27] Prodpran T., Benjaku S. A. properties and microstructure of proteinbasedlfilm from round scad (Decapterus maruadsi) muscle as affected by palm oil and chitosan incorporation. International Journal of Biological Macromolecules, 2007;41: 605-614.

[28] Saraswathy G., Pal S., Rose C., Sastry T. P. A novel bio-inorganic bone implant containing deglued bone, chitosan and gelatin. Indian Academy of Sciences, Bulletin of Material Science, 2001;24: 415-420.

[29] Wanchoo R. K., Sharma P. K. Viscometric study on the compatibility of some water- soluble polymer-polymer mixtures. Europeans Polymer Journal, 2003;39:1481-1490.

[30] Abreu D. A., Paseiro P. L., Nngulo I., Cruz J. M. Development of new polyolefin films with nanoclays for application in food packaging. Europeans Polymer Journal, 2007;43: 2229-2243.

[31] Kusumastuti Y., Timotius D., Putri1 N. R., Syabani M. W., Rochmadi. Rheological and kinetic studies of low density polyetyhlene (LDPE) - chitosan biocomposite film. IOP Conference Series: Journal of Material Science and Engineering, 2020;722: 012054. doi:10.1088/1757-899X/722/1/012054.

[32] Quiroz C. J., Rodríguez F. D., Grijalva M. H. Preparation of extruded polyethylene / chitosan blends compatibilized with polyethylene- graft -maleic anhydride. Journal of Carbohydrate Polymer, 2014;101: 1094-1100.

[33] Olajide A., Okoronkwo A. E., Oluwasina O. O., Abe T. O. Utilization of blue crab shells for the synthesis of chitosan nanoparticles and their characterization. Songklanakarin Journal of Science Technology, 2018;40 (5): 1043-1047.

[34] Wan Y., Wu H., Yu A., Wen D. Biodegradable Polylactide/Chitosan Blend Membranes. Journal of Biomacromolecules, 2006;7: $1362-1372$.

[35] Bhawna S., Barakat M., Sam C., Emad M. E., El Barbary H. Physicochemical, antimicrobial and antioxidant properties of chitosan/TEMPO biocomposite packaging films. Journal of Food Packaging and Shelf Life, 2018;17: 73-79.

[36] Chatchai V., Worawat W., Suttipong W., Yuranan H., Kankavee S., Nollapan N., Siwaruk C., Witchukorn P., Suchada J., Apirat L. Antimicrobial, Conductive, and Mechanical Properties of AgCB/PBS Composite System. Journal of Chemistry, 2009. ID:3487529.

[37] Soni B., Schilling W., Hassan E. B., Mahmoud B. Transparent bionanocomposite films based on chitosan and TEMPO-oxidized cellulose nanofibers with enhanced mechanical and barrier properties. Journal of Carbohydrate Polymers, 2016;51: 779-789.

[38] Tharanathan R. N. Biodegradable films and composite coatings: past, present and future. Trends in Food Science and Technology, 2013;14: 71-78. 